www.nature.com/ja

\title{
Aranciamycin anhydride, a new anthracycline-type antibiotic isolated from Streptomyces sp. Tü 6384*
}

\author{
Jonny Nachtigall ${ }^{1,4}$, Dirk Schulz ${ }^{2,4}$, Winfried Beil ${ }^{3}$, Roderich D Süssmuth ${ }^{1}$ and Hans-Peter Fiedler ${ }^{2}$
}

The Journal of Antibiotics (2010) 63, 397-399; doi:10.1038/ja.2010.59; published online 16 June 2010

Keywords: anthracycline antibiotic; antitumor activity; Streptomyces

Streptomycetes isolated from the rhizosphere of Norway spruce were grown in submerged culture in various complex media, and extracts prepared from culture filtrates and biomass were screened by HPLCdiode array analysis to detect novel secondary metabolites. ${ }^{2}$ Strain Tü 6384 was found to produce a new anthracycline-type compound that showed a high similarity with aranciamycin, an antibiotic isolated from Streptomyces echinatus, in its UV-visible spectrum. ${ }^{3}$ The compound was characterized as aranciamycin anhydride (1).

Strain Tü 6384 was isolated from the rhizosphere of Norway spruce collected in Rammert forest near Tübingen, Germany. It was examined for a number of key properties that are known to be of value in streptomycete systematics. ${ }^{4,5}$ Whole-cell hydrolysates of strain Tü 6384 contained LL-diaminopimelic acid, and hexa- and octahydrogenated menaquinones with nine isoprene units were the predominant isoprenologs. Partial sequencing of the $16 \mathrm{~S}$ rRNA gene led to a similarity of $99 \%$ with Streptomyces prunicolor.

Batch fermentations of strain Tü 6384 were carried out in a 10-1 stirred tank fermentor (Biostat S; B Braun, Melsungen, Germany) in a complex medium that consisted of (per liter tap water) oatmeal (Holo Hafergold, Neuform, Germany) $20 \mathrm{~g}$, and $5 \mathrm{ml}$ of a trace element solution that was composed of (per liter deionized water) $\mathrm{CaCl}_{2} \times 2 \mathrm{H}_{2} \mathrm{O} 3 \mathrm{~g}$, iron(III) citrate $1 \mathrm{~g}, \mathrm{MnSO}_{4} \times 1 \mathrm{H}_{2} \mathrm{O} 200 \mathrm{mg}$, $\mathrm{ZnCl}_{2} 100 \mathrm{mg}, \mathrm{CuSO}_{4} \times 5 \mathrm{H}_{2} \mathrm{O} 25 \mathrm{mg}, \mathrm{Na}_{2} \mathrm{~B}_{4} \mathrm{O}_{7} \times 10 \mathrm{H}_{2} \mathrm{O} 20 \mathrm{mg}$, $\mathrm{CoCl}_{2} \times 6 \mathrm{H}_{2} \mathrm{O} 4 \mathrm{mg}$ and $\mathrm{Na}_{2} \mathrm{MoO}_{4} \times 2 \mathrm{H}_{2} \mathrm{O} 10 \mathrm{mg}$; the $\mathrm{pH}$ was adjusted to $7.3(5 \mathrm{M} \mathrm{HCl})$ before sterilization. The fermentor was inoculated with $5 \%$ by volume of a shake flask culture grown in a seed medium at $27^{\circ} \mathrm{C}$ in $500-\mathrm{ml}$ Erlenmeyer flasks with a single baffle for $72 \mathrm{~h}$ on a rotary shaker at 120 r.p.m. The seed medium consisted of glucose $10 \mathrm{~g}$, glycerol $10 \mathrm{~g}$, oatmeal $5 \mathrm{~g}$, soybean meal (Schoenenberger, Magstadt, Germany) $10 \mathrm{~g}$, yeast extract (Ohly Kat, Deutsche Hefewerke, Hamburg, Germany) $5 \mathrm{~g}$, Bacto Casamino acids $5 \mathrm{~g}$ and $\mathrm{CaCO}_{3} 1 \mathrm{~g}$ in 11 tap water. The fermentation was carried out for 4 days with an aeration rate of 0.5 volume air per volume per min and agitation at 250 r.p.m. The production of 1 reached a maximal yield of $50 \mathrm{mgl}^{-1}$ at $72 \mathrm{~h}$ of incubation. The culture filtrate (61) was applied to an Amberlite XAD- 16 column $(60 \times 4 \mathrm{~cm}$ i.d.; Rohm and Haas, Frankfurt, Germany), washed with each of $31 \mathrm{H}_{2} \mathrm{O}$ and $\mathrm{H}_{2} \mathrm{O}-\mathrm{EtOH}$ (6:4), and 1 was eluted with $31 \mathrm{EtOH}$ and concentrated in vacuo. The crude product was dissolved in $\mathrm{CH}_{2} \mathrm{Cl}_{2}$ and added to a diol-modified silica gel column $(45 \times 2.6 \mathrm{~cm}$ i.d., LiChroprep Diol; Merck, Darmstadt, Germany). The separation was accomplished by a step gradient from $\mathrm{CH}_{2} \mathrm{Cl}_{2}$ to $5 \% \mathrm{EtOH}$. The combined fractions containing 1 were concentrated in vacuo and yielded $385 \mathrm{mg}$ crude product, which was purified by preparative RP-HPLC (Nucleosil-100 C-18, $10 \mu \mathrm{m}$, $25 \times 1.6 \mathrm{~cm}$ i.d.; Maisch, Ammerbuch, Germany) with $\mathrm{CH}_{3} \mathrm{CN}-0.1 \%$ $\mathrm{HCOOH}$ using a linear gradient elution from 40 to $80 \% \mathrm{CH}_{3} \mathrm{CN}$ over $20 \mathrm{~min}$ at a flow rate of $20 \mathrm{ml} \mathrm{min}^{-1}$. Compound $1,45 \mathrm{mg}$, was obtained as a red-orange powder (Table 1).

The molecular mass of $\mathbf{1}$ was determined by high-resolution electrospray ionization-FT-ion cyclotron resonance mass spectrometry, which gave the mass of 710.17728, suggesting a molecular formula of $\mathrm{C}_{35} \mathrm{H}_{34} \mathrm{O}_{16}$ (theoretical: 709.17741, $\Delta=0.13$ p.p.m.). The chemical structure of 1 as shown in Figure 1 was determined by ${ }^{1} \mathrm{H}-,{ }^{13} \mathrm{C}$ - and 2D-NMR experiments (Table 2) and GC-MS. The complete NMR assignments were unambiguously carried out on the basis of COSY and heteronuclear multiple bond correlation (HMBC) experiments. The ${ }^{1} \mathrm{H}-\mathrm{NMR}$ and heteronuclear single quantum coherence (HSQC) data showed a total of 30 carbon-attached protons, among which five methyl, two methylene and eleven methine carbons could be assigned. Inspection of the 2D-NMR data (COSY, HSQC and HMBC) allowed assignment of the structure of $\mathbf{1}$, a new derivative of the aranciamycin family, aranciamycin anhydride (Figure 2). The ${ }^{1} \mathrm{H}-{ }^{1} \mathrm{H}-\mathrm{COSY}$ spectra of 1 revealed protons attached to two ethyl, one phenyl and one sugar (hexose) moiety, as shown by the bold lines in Figure 2. All expected

${ }^{1}$ Institut für Chemie, Technische Universität Berlin, Berlin, Germany; ${ }^{2}$ Mikrobiologisches Institut, Universität Tübingen, Tübingen, Germany and ${ }^{3}$ Institut für Pharmakologie, Medizinische Hochschule Hannover, Hannover, Germany

${ }^{4}$ These authors contributed equally to this work.

Correspondence: Professor H-P Fiedler, Mikrobiologisches Institut, Universität Tübingen, Auf der Morgenstelle 28, Tübingen 72076, Germany.

E-mail: hans-peter.fiedler@uni-tuebingen.de or Professor RD Süssmuth, Institut für Chemie, Technische Universität Berlin, Straße des 17. Juni 124, Berlin 10623, Germany.

E-mail: suessmuth@chem.tu-berlin.de

*Art. No. 55 in 'Biosynthetic Capacities of Actinomycetes'. Art. No. 54: see ref 1.

Received 18 February 2010; revised 18 March 2010; accepted 11 April 2010; published online 16 June 2010 
Table 1 Physico-chemical properties of aranciamycin anhydride ${ }^{1}$

\begin{tabular}{ll}
\hline & 1 \\
\hline Appearance & Red-orange powder \\
Optical rotation ${ }^{a}$ & {$[\alpha]^{20}+82^{\circ}(\mathrm{c} .0 .05, \mathrm{MeOH})$} \\
FT-ICR-MS $^{b}$ & 709.17728 found $(\mathrm{M}-\mathrm{H})^{-}$ \\
& 709.17741 calculated $(\mathrm{M}-\mathrm{H})^{-}$ \\
& $\Delta=0.13$ p.p.m. \\
Molecular formula & $\mathrm{C}_{35} \mathrm{H}_{34} \mathrm{O}_{16}$ \\
UVc $_{\text {max }}(\mathrm{MeOH}) \mathrm{nm}(\log \varepsilon)$ & $240(4.48), 260(4.44), 435(4.08)$ \\
IR $^{\mathrm{d}} \mathrm{V}_{\max }\left(\mathrm{cm}^{-1}\right)$ & $3503,2977,2933,1766,1715,1675,1625$, \\
& $1448,1415,1380,1290,1247,1191,1170$, \\
& $1135,1109,1083,1031,1001,957,840$, \\
& 758,735
\end{tabular}

Abbreviation: ICR, ion cyclotron resonance.

aptical rotation was recorded on a 341 polarimeter (Perkin-Elmer, Überlingen, Germany). bHR-FT-ICR-MS measurement was carried out on an APEX II FT-ICR mass spectrometer (4.7 T, Bruker-Daltonics, Bremen, Germany).

CUV-visible spectra were obtained on a HP 1090M diode array detector (Agilent Technologies, Waldbronn, Germany).

dInfrared data measurement was carried out on an 881 IR-spectrometer (Perkin-Elmer)

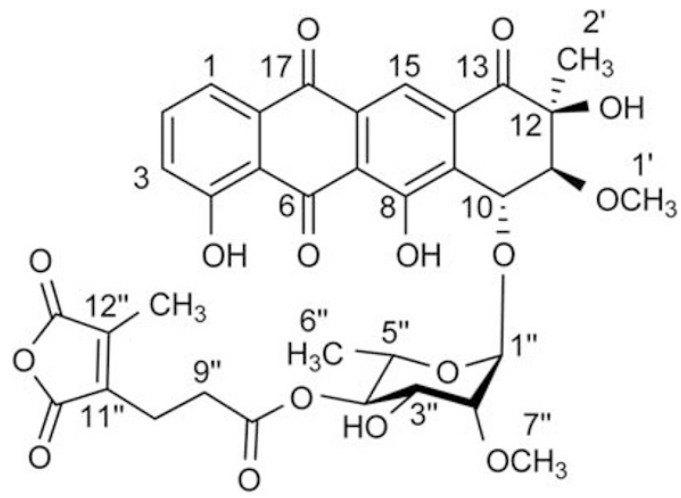

Figure 1 Structure of aranciamycin anhydride (1).

HMBC correlations of the aranciamycin moiety could be seen and couplings were in good accordance with the data given in literature. ${ }^{6}$ The connection between the sugar moiety and the aranciamycin chromophore was established by the ${ }^{1} \mathrm{H}-{ }^{13} \mathrm{C}-$ long-range coupling from C-10 $\left(\delta_{\mathrm{H}} 5.19, \delta_{\mathrm{C}} 72.4\right)$ to $\mathrm{H}-1^{\prime \prime}\left(\delta_{\mathrm{H}} 5.65, \delta_{\mathrm{C}} 100.5\right)$ and vice versa as shown in Figure 2. The constitution of the sugar was determined from COSY and HMBC spectra, which revealed a 6desoxyhexose moiety. The coupling constants (Table 3 ) indicated that the sugar was a mannopyranose. $\mathrm{A}^{1} \mathrm{H}-{ }^{13} \mathrm{C}$ long-range coupling from the methyl group at $\delta_{\mathrm{H}} 3.56$ to $\mathrm{C}-2^{\prime \prime}\left(\delta_{\mathrm{C}} 80.3\right)$ of the sugar established the position of the methoxy group. Additional examination of the NMR data and chiral GC-MS analysis of the derivatized hydrolysate allowed us to identify the moiety as $\beta-2-O$-methyl-L-rhamnose in accordance with the literature. ${ }^{7}$ In comparison with the molecular formula of aranciamycin, derivative $\mathbf{1}$ has an additional $\mathrm{C}_{8} \mathrm{H}_{6} \mathrm{O}_{4}$ moiety. In addition, the NMR spectra showed five quaternary olefinic, two methylene and one methyl moiety compared with the aranciamycin core structure. The ${ }^{1} \mathrm{H}-{ }^{13} \mathrm{C}$ long-range couplings from $\mathrm{H}-9{ }^{\prime \prime}$ $\left(\delta_{\mathrm{H}} 2.77\right)$ to $\mathrm{C}-8^{\prime \prime}\left(\delta_{\mathrm{C}} 171.8\right), \mathrm{C}-10^{\prime \prime}\left(\delta_{\mathrm{C}} 19.9\right)$ and $\mathrm{C}-11^{\prime \prime}\left(\delta_{\mathrm{C}} 142.0\right)$, from $\mathrm{H}-10^{\prime \prime}\left(\delta_{\mathrm{H}} 2.78\right)$ to C-8" ${ }^{\prime \prime}, \mathrm{C}-9^{\prime \prime}\left(\delta_{\mathrm{C}} 31.3\right)$ and C-14" $\left(\delta_{\mathrm{C}} 165.8\right)$, and from $\mathrm{H}-15^{\prime \prime}\left(\delta_{\mathrm{H}} 2.10\right)$ to $\mathrm{C}-11^{\prime \prime}, \mathrm{C}-12^{\prime \prime}\left(\delta_{\mathrm{C}} 142.6\right)$ and $\mathrm{C}-13^{\prime \prime}\left(\delta_{\mathrm{C}}\right.$ $166.1)$ gave rise to an anhydride structure in excellent accordance with literature values. ${ }^{8}$ The connection between the sugar and the anhy-
Table $2{ }^{1} \mathrm{H}$ - and ${ }^{13} \mathrm{C}$-NMR assignment of 1 in $\mathrm{CDCl}_{3}-d\left(25^{\circ} \mathrm{C}\right)$

\begin{tabular}{|c|c|c|}
\hline Position & $\delta\left({ }^{1} H\right)($ p.p.m. $) \mathrm{J}$ in $\mathrm{Hz}$ & $\delta\left({ }^{13}\right.$ C) (p.p.m.) \\
\hline 1 & $7.88(d, 7.5)$ & 120.9 \\
\hline 2 & $7.75(t, 7.9)$ & 138.5 \\
\hline 3 & $7.34(\mathrm{~d}, 8.3)$ & 125.3 \\
\hline 4 & - & 163.2 \\
\hline 5 & - & 115.9 \\
\hline 6 & - & 193.2 \\
\hline 7 & - & 119.1 \\
\hline 8 & - & 162.5 \\
\hline 9 & - & 133.3 \\
\hline 10 & $5.19(\mathrm{~d}, 2.4)$ & 72.4 \\
\hline 11 & $3.72(\mathrm{~d}, 2.5)$ & 85.9 \\
\hline 12 & - & 76.9 \\
\hline 13 & - & 198.9 \\
\hline 14 & - & 136.3 \\
\hline 15 & $8.41(\mathrm{~s})$ & 118.0 \\
\hline 16 & - & 134.0 \\
\hline 17 & - & 180.6 \\
\hline 18 & - & 133.6 \\
\hline $1^{\prime}$ & $3.54(\mathrm{~s})$ & 60.3 \\
\hline $2^{\prime}$ & $1.54(\mathrm{~s})$ & 23.1 \\
\hline $1^{\prime \prime}$ & $5.65(\mathrm{~s}, \mathrm{br})$ & 100.5 \\
\hline $2^{\prime \prime}$ & $3.53(\mathrm{dd}, 1.4 ; 3.6)$ & 80.3 \\
\hline $3^{\prime \prime}$ & $3.59(\mathrm{dd}, 3.6 ; 9.8)$ & 69.6 \\
\hline $4^{\prime \prime}$ & $4.87(\mathrm{dd}, 9.8 ; 9.8)$ & 75.1 \\
\hline $5^{\prime \prime}$ & $3.92(\mathrm{dq}, 9.8 ; 6.2)$ & 67.6 \\
\hline $6^{\prime \prime}$ & $1.23(\mathrm{~d}, 6.2)$ & 17.7 \\
\hline $7^{\prime \prime}$ & $3.56(\mathrm{~s})$ & 59.0 \\
\hline $8^{\prime \prime}$ & - & 171.8 \\
\hline $9^{\prime \prime}$ & $2.77(\mathrm{~m})$ & 31.3 \\
\hline $10^{\prime \prime}$ & $2.78(\mathrm{~m})$ & 19.9 \\
\hline $11^{\prime \prime}$ & - & 142.0 \\
\hline $12^{\prime \prime}$ & - & 142.6 \\
\hline $13^{\prime \prime}$ & - & 166.1 \\
\hline $14^{\prime \prime}$ & - & 165.8 \\
\hline $15^{\prime \prime}$ & $2.10(\mathrm{~s})$ & 9.7 \\
\hline
\end{tabular}

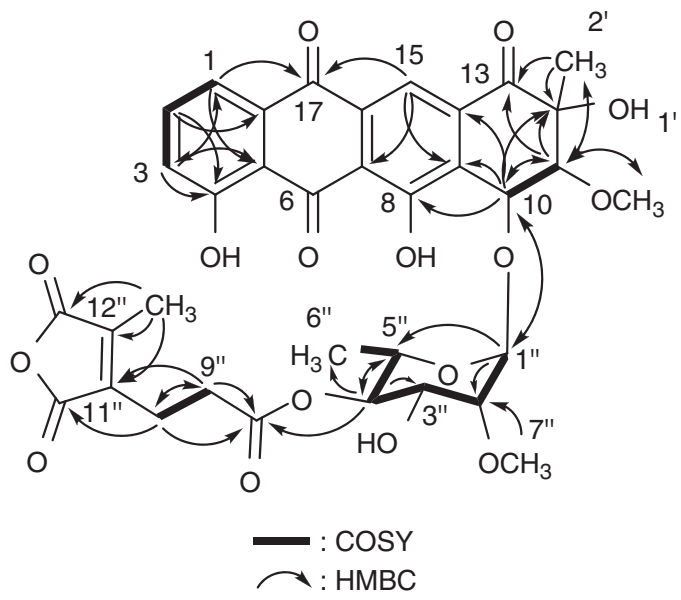

Figure $2{ }^{1} \mathrm{H}-{ }^{1} \mathrm{H}-\mathrm{COSY}$ and $\mathrm{HMBC}$ correlations observed in $\mathbf{1}$.

dride moiety was established by the ${ }^{1} \mathrm{H}-{ }^{13} \mathrm{C}$ long-range coupling observed from $\mathrm{H}-4^{\prime \prime}\left(\delta_{\mathrm{H}} 4.87\right)$ to the carbonyl of $\mathrm{C}-8^{\prime \prime}$, resulting in the structure of $\mathbf{1}$ (Figure 1). 
Table 3 Growth-inhibitory activity of 1 and aranciamycin ( $\mu \mathrm{g} \mathrm{ml}^{-1}$ ) against selected human tumor cell lines

\begin{tabular}{lcclll}
\hline & \multicolumn{2}{c}{1} & \multicolumn{2}{c}{ Aranciamycin } \\
\cline { 2 - 3 } Cell line & GI $_{50}$ & TGI & & Gl & TGI \\
\hline HM02 & 6.5 & $>10$ & 0.62 & 1.35 \\
HepG2 & 7.2 & $>10$ & 1.15 & 3.2 \\
MCF 7 & $>10$ & $>10$ & 1.3 & 3.3
\end{tabular}

Abbreviations: $\mathrm{Gl}_{50}, 50 \%$ growth inhibition; TGI, 100\% growth inhibition.

The antimicrobial activity spectrum of $\mathbf{1}$ was tested in an agar plate diffusion assay against Bacillus subtilis DSM 10, Escherichia coli K12, Saccharomyces cerevisiae ATCC 9010 and Botrytis cinerea Tü 157 in a concentration of $0.1-1 \mathrm{mg} \mathrm{ml}^{-1}$. Similar to aranciamycin, 1 showed weak antibacterial activity only against Bacillus subtilis. The inhibitory action of $\mathbf{1}$ on the growth of tumor cells was compared with aranciamycin and tested according to $\mathrm{NCI}$ guidelines ${ }^{9}$ with the human tumor cell lines HM02 (gastric adenocarcinoma), MCF 7 (breast carcinoma) and HepG2 (hepatocellular carcinoma). Cells were grown in 96-well microtiter plates in RPMI 1640 with $10 \%$ fetal calf serum in a humidified atmosphere of $5 \% \mathrm{CO}_{2}$ in air. Aranciamycin and $1\left(0.1-10 \mu \mathrm{g} \mathrm{ml}^{-1}\right)$ were added to the cells after incubation for $24 \mathrm{~h}$. Stock solutions were prepared in DMSO; the final DMSO concentration of the cultures was $0.1 \%$. The cells were fixed and cell protein analyzed with sulforhodamine B after incubation for $48 \mathrm{~h}$. The cytostatic activity of $\mathbf{1}$ was somewhat less than that of aranciamycin (Table 3).

\section{ACKNOWLEDGEMENTS}

Financial support from the Deutsche Forschungsgemeinschaft (Graduate College 685 'Infection Biology'; DS), the European Commission (project ACTINOGEN, 6th framework, Grant LSHM-CT-2004-005224; RDS), and Bayer Schering Pharma AG (Berlin, Germany) is gratefully acknowledged. We thank Mr A Kulik, Universität Tübingen, for assistance in fermentations.

1 Abdel-Mageed, W. M. et al. Dermacozines, a new phenazine family from deep-sea dermacocci isolated from a Mariana Trench sediment. Org. Biomol. Chem. 8, 2352-2362 (2010).

2 Fiedler, H.- P. Biosynthetic capacities of actinomycetes. 1. Screening for novel secondary metabolites by HPLC and UV-visible absorbance spectral libraries. Nat. Prod. Lett. 2, 119-128 (1993).

3 Keller-Schierlein, W., Sauerbier, J., Vogler, U. \& Zähner, H. Stoffwechselprodukte von Mikroorganismen-Aranciamycin. Helv. Chim. Acta 53, 779-789 (1970).

4 Williams, S. T., Goodfellow, M. \& Alderson, G. Genus Streptomyces Waksman and Henrici 1943, 339AL. in Bergey's Manual of Systematic Bacteriology, Vol. 4 (eds. Williams, S.T. et al.) 2452-2492 (Williams \& Wilkins, Baltimore, 1989).

5 Manfio, G. P., Zakrzewska-Czerwinska, J., Atalan, E. \& Goodfellow, M. Towards minimal standards for the description of Streptomyces species. Biotekhnologiya 8, 228-237 (1995).

6 Bols, M., Binderup, L., Hansen, J. \& Rasmussen, P. Inhibition of collagenase by aranciamycin and aranciamycin derivatives. J. Med. Chem. 35, 2768-2771 (1992).

7 Keller-Schierlein, W. \& Müller, A. The sugar component of aranciamycin: 2-O-methylrhamnose. Experientia 26, 929-930 (1970).

8 Naganawa, A., Ichikawa, Y. \& Isobe, M. Synthetic studies on tautomycin: synthesis of 2,3-disubstituted maleic anhydride segment. Tetrahedron 50, 8969-8982 (1994).

9 Grever, M. R., Shepartz, S. A. \& Chabner, B. A. The National Cancer Institute: cancer drug discovery and development program. Semin. Oncol. 19, 622-638 (1992). 